\title{
Open Distal Gastrectomy versus Laparoscopic Distal Gastrectomy: As Influenced by Facility Background Factors in the Real World
}

\author{
Nozomu Murakami ${ }^{*}$, Shinichi Kadoya ${ }^{2}$, Masanari Shimada ${ }^{3}$, Naoki Endo, \\ Kaname Ishiguro', Koichiro Sawada ${ }^{1}$, Kouichi Tanabe ${ }^{4}$, Hatsuna Yasuda ${ }^{4}$, \\ Noriyuki Inaki ${ }^{5}$, Tetsuji Yamada', Eiji Kanehira ${ }^{6}$, Tatsuhiko Kashii ${ }^{4}$ \\ ${ }^{1}$ Department of Surgery, Saiseikai Takaoka Hospital, Toyama Prefecture, Takaoka, Japan \\ ${ }^{2}$ Department of General and Cardiothoracic Surgery, Kanazawa University, Kanazawa, Japan \\ ${ }^{3}$ Department of Surgery, Fukui Saiseikai Hospital, Fukui, Japan \\ ${ }^{4}$ Department of Medical Oncology, Toyama University Hospital, Toyama, Japan \\ ${ }^{5}$ Department of Surgery, Ishikawa Prefectural Central Hospital, Kanazawa, Japan \\ ${ }^{6}$ Department of Surgery, Medical Topia Soka, Soka, Japan \\ Email: nozomu1231@takaoka-saiseikai.jp
}

Received 21 January 2014; revised 20 February 2014; accepted 27 February 2014

Copyright (C) 2014 by authors and Scientific Research Publishing Inc.

This work is licensed under the Creative Commons Attribution International License (CC BY). http://creativecommons.org/licenses/by/4.0/

(c) (i) Open Access

\section{Abstract}

The purpose of our study was to retrospectively evaluate the clinical efficacy and safety of laparoscopy assisted distal gastrectomy (LADG) performed by one operating and advising surgeon in patients with gastric cancer over a period of 10 years. We examined the choice of anastomosis techniques, and compared the duration of surgery, blood loss, number of dissected lymph nodes and intraoperative complications for LADG and open distal gastrectomy (ODG). We studied 254 patients who underwent laparoscopic gastrectomy and 36 patients who underwent ODG. 169 of 254 patients received LADG. Duration of surgery was significantly longer for LADG than that for ODG, blood loss was significantly smaller, and numbers of dissected lymph nodes were similar. With LADG, there was anastomotic leakage in 2 patients and postoperative obstruction in 2 patients. No recurrence of disease and no deaths have been reported to date. Though previous clinical trials have shown that LADG is less invasive, our study of LADG in the real world did not show superiority, but rather equivalence to ODG in terms of other outcomes. This study could be advantageous to evaluate the clinical efficacy and safety of LADG without having to take into account multiple surgeons' technical levels and the background differences between the facilities.

${ }^{*}$ Corresponding author.

How to cite this paper: Murakami, N., et al. (2014) Open Distal Gastrectomy versus Laparoscopic Distal Gastrectomy: As Influenced by Facility Background Factors in the Real World. Surgical Science, 5, 97-104.

http://dx.doi.org/10.4236/ss.2014.53019 


\section{Keywords}

\section{Gastric Cancer; Laparoscopic Surgery; Gastrectomy; General Hospital}

\section{Introduction}

Laparoscopic assisted distal gastrectomy (LADG) has attracted attention as a less invasive approach to opening surgery for the treatment of gastric cancer [1]-[5]. This technique is currently applied in Japanese university hospitals, cancer treatment facilities, and general acute hospitals in accordance with the Guidelines for Diagnosis and Treatment of Carcinoma of the Stomach. Although previous studies have shown the safety and efficacy of LADG [2] [6]-[8], LADG is still under clinical investigation and an alternative procedure while open distal gastrectomy (ODG) is a standard procedure. Moreover, some surgeons think that the LADG procedure requires high skill and experience on the part of operating surgeons [8] [9]. These reasons could become the factors that hinder the implementation of LADG. This study retrospectively investigated the surgical treatments of gastric cancer patients over a period of 10 years as performed by one operating and advising surgeon. The purpose of this study was to evaluate the clinical efficacy and safety of LADG compared with ODG without having to take into account multiple surgeons' technical levels and experience.

\section{Methods}

The surgeon performed either LADG or ODG on patients with gastric cancer over a period of 10 years and we retrospectively compared the outcomes of both groups of patients.

\subsection{Subjects}

We selected from the data of patients with gastric cancer who were hospitalized and received LADG or ODG at either Ishikawa Prefectural Central Hospital (2002-2006) or Saiseikai Takaoka Hospital, Toyama prefecture (2007-2011), both of which the one operating and advising surgeon was affiliated with during the time period. Both facilities are hub hospitals in an oncology care network. There are 662 registered beds and 9 surgeons at Ishikawa Prefectural Central Hospital and 266 registered beds and 4 surgeons at Saiseikai Takaoka Hospital. The surgical instruments used to perform LADG or ODG are equivalent at both facilities.

\subsection{LADG Selection Criteria}

Treatment with LADG is indicated for patients with c-stage 1A or 1B disease according to the 13th Japanese Classification of Gastric Cancer [10]. After we explained to the patients that LADG was under clinical investigation and ODG was a standard procedure, patients ultimately selected their preferred surgical method. For lymph node dissection, we perform D1 $+\alpha$ or $\beta$ for T1N0 and D2 for T2 or N1.

\subsection{Surgical Technique}

\subsubsection{ODG and LADG Procedures}

ODG is a surgical procedure to perform a surgical incision into the abdominal wall from the xiphoid process to the upper umbilici of patients in a supine position. Lymph node dissection is done in accordance with the stage of gastric cancer progression at laparotomy after the greater omentum and gastrocolic ligaments are dissected outside the epigastric arcade by using ultrasonically activated coagulating shears and the vessel sealing system [11].

On the other hand, in the LADG procedure, a port for laparoscopy is inserted at the umbilical position of patients in broad base, and the other four ports are placed at the upper abdomen while under laparoscopic observation. After the greater omentum and gastrocolic ligaments are dissected outside the epigastric arcade by using laparoscopic ultrasonically activated coagulating shears and the vessel sealing system, lymph node dissection is done through the stoma in accordance with the stage of gastric cancer progression by using $5 \mathrm{~mm}$ forceps and clips for hemostasis in the collaboration with assistant surgeon After the lower two-thirds of the stomach is mo- 
bilized under laparoscopic procedures, a 5-cm midline skin incision is carried out just under the xiphoid. The distal portion of the stomach is extracted extracorporeally with an autosuture stapler through the 5-cm skin incision [12].

Both procedures require the regional lymph nodes to be dissected inconjunction with the distal portion of the stomach. Gastroduodenostomy or Roux-en-Y anastomosis is performed to close the abdominal wall after hemostasis.

\subsubsection{Reconstruction Methods}

The Billroth-I (B-I) method was the most commonly used method for distal gastrectomy (DG), and manual and mechanical suturing were generally used in equal measures [13]. In contrast, the Roux-en-Y (R-Y) method was the most commonly used when performing a total gastrectomy (TG) [14].

The B-I and manual suturing methods were used more frequently during the first 3 years of the study period, after which they were replaced by the hemi-double-stapling technique (HDST) and the posterior-wall perforation method. Manual suturing was not used from 2007 onwards, and HDST was not used after 2008. Only the posterior-wall perforation and the R-Y methods were performed with the B-I method [15]-[18].

\subsection{Outcome/Indication}

We observed the annual change in the rate of LAG procedures performed and compared LADG and ODG in terms of preoperative, procedural and postoperative outcomes such as: time in surgery, blood loss, number of lymph nodes dissected, procedural or postoperative complications (including those associated with different suturing techniques used for LADG) and the number of days of postoperative hospitalization. We classified postoperative complications in accordance with Clavien-Dindo classification.

\subsection{Statistical Analysis}

Postoperative complications of LADG and ODG are compared in Table 1. Quantitative variables, such as age, surgical time, bleeding volume, the length of postoperative hospital stay, and number of lymph nodes dissected were compared between the LADG and ODG groups using Welch's t-test. Nominal variables, such as the number of cases, incidence of postoperative complication, and incidence of procedural accidents, were compared using the chi-square test. The significance level was established as 0.05 . All statistical analyses were conducted using the statistical software, Ekuseru-Toukei 2012 (SSRI Co., Ltd.).

\subsection{Ethics}

This retrospectively observed study was approved by general consentwithin ethical guidelines for epidemiolog-

\begin{tabular}{ccc}
\hline Table 1. Postoperative complications of ODG and LADG. & \\
\hline Postoperative Complications & ODG $(\%)$ & LADG (\%) \\
\hline Hemorrhage & $0(0.0)$ & $3(1.8)$ \\
Stenosis/Passage difficulty & $1(2.8)$ & $2(1.2)$ \\
Ruptured suture & $0(0.0)$ & $3(1.8)$ \\
Intraperitoneal abscess & $0(0.0)$ & $1(0.6)$ \\
Pancreatitis/pancreatic fistula & $0(0.0)$ & $0(0.0)$ \\
Ileus & $0(0.0)$ & $2(1.2)$ \\
Respiratory complications & $1(2.8)$ & $3(1.8)$ \\
Wound infection & $1(2.8)$ & $0(0.0)$ \\
Wound metastasis & $0(0.0)$ & $6(3.6)$ \\
Others & $2(5.6)$ & $21(12.4)$ \\
\hline
\end{tabular}

Open distal gastrectomy (ODG), laparoscopic assisted distal gastrectomy (LADG). 
ical research, as defined by Ministry of Education, Culture, Sports, Science and Technology and Ministry of Health, Labour, and Welfare in Japan. The study design was approved by an institutional review board. We obtained informed consent after explaining the merit and demerit of LADG procedureto each patient.

\section{Results}

\subsection{Patient Characteristics and Rates of Laparoscopic Assisted Gastrectomy Procedures}

254 patients were treated with LAG and 36 patients underwent open gastrectomy over a period of 10 years. During that period, the operative surgeon performed at two hospitals: the Ishikawa Prefectural Central Hospital (2002-2006) and the Saiseikai Takaoka Hospital in Toyama prefecture (2007-2011).

$96 \%$ of the patients overall had c-stage IA or IB disease at the time of surgery, and $85 \%$ had stage IA disease. In the 254 patients who underwent laparoscopic assisted surgery, surgical procedures were performed as follows: distal gastrectomy (LADG: $n=169$ ), pylorus-preserving gastrectomy (LAPPG: $n=38$ ), total gastrectomy (LATG: $n=23$ ), proximal gastrectomy (LAPG: $n=16)$, endoscopic cooperative surgery, (LECS: $n=3$ ) and exploratory laparoscopy $(n=5)$. The number of patients treated with LADG increased annually from 2002 onwards, exceeding $40 \%$ during 2006. The average change in the annual rate of LAG procedures performed over the 10 -year study period was 36\%; the rate increased from about $30 \%$ in 2002 to $70 \%$ in 2010 .

\subsection{Complications}

Procedural complications with LADG included hemorrhaging $(\mathrm{n}=1)$ and the need to switch to open abdominal surgery $(n=2)$. During one LADG procedure, the stump of the right gastroepiploic artery hemorrhaged towards the end of surgery because a clipless technique was used. The clipless technique is one of the methods used to seal vessels with ultrasonic waves using laparoscopic ultrasonic coagulating shears for vessels that are less than $7 \mathrm{~mm}$ in diameter. Vessels greater than $7 \mathrm{~mm}$ in diameter are sealed with voltage using an electrothermal bipolar vessel sealer [19] [20].

Postoperative complications in relation to LADG also included hemorrhaging ( $n=3$, Grade IIIb). The LADG was performed including the clipless technique in one of these patients, and the others had blood loss from the site of the drain, with no active hemorrhage observed upon reopening the abdomen (Table 1).

Sutures ruptured in 2 patients who had been treated with LADG using the B-I and manual suturing methods. These were among the first 20 patients to undergo the procedure after the introduction of LADG. Stenosis was observed in one patient whose surgery was performed via the R-Y method, and an automatic suturing device was used to close the stapler insertion hole used for anastomosis of the remaining stomach and jejunum. Stasis was observed in 2 patients that had been treated as some of the first cases after LADG introduction and it tended to happen after the removal of the small stomach.

\subsection{Comparison of Laparoscopic and Open Distal Gastrectomy}

The duration of LADG surgery was significantly longer than ODG, and blood loss and the number of days in the hospital after surgery were significantly shorter. Although the definition of c-stage was not the same in all patients, there was no difference between the procedures in the number of lymph nodes dissected or the incidence of complications. In another case, a switch from the B-I method to open abdominal surgery was necessary to repair the end of the duodenum, which was cut because of difficulties inserting an anvil. Reconstruction was performed using the R-Y method. During the study period, neither recurrence of disease or deaths were reported in patients whose disease was classified as stage c-IB or lower (Table 2).

\section{Discussion}

This study focuses on LADG and ODG procedures performed by just one operating and advising surgeon, thus removing the factor of surgeons' technical experience and abilities and could corroborate solely the clinical efficacy and safety of LADG.

We evaluated trends in the implementation of LADG over a period of 10 years and observed an increase in the rate of LADG procedures performed on patients undergoing surgery for gastric cancer, raising from around $30 \%$ of patients in 2002 to $70 \%$ by 2010. A comparison of perioperative outcomes of LADG and ODG over this 
Table 2. ODG vs. LADG.

\begin{tabular}{|c|c|c|c|}
\hline & ODG & LADG & $p$ value \\
\hline Number of cases (male/female) & $36(21 / 15)$ & $169(82 / 87)$ & $0.29^{\ddagger}$ \\
\hline Age (years, mean $\pm \mathrm{SD}$ ) & $73.1 \pm 15.8$ & $63.6 \pm 11.6$ & $0.0013^{* \dagger}$ \\
\hline \multicolumn{4}{|l|}{ Clinical stage } \\
\hline IA & 12 & 142 & $<0.001^{* \ddagger}$ \\
\hline IB & 5 & 21 & $0.97^{\ddagger}$ \\
\hline II & 3 & 5 & $0.29^{\ddagger}$ \\
\hline IIIA & 4 & 0 & $0.0002^{* \ddagger}$ \\
\hline IIIB & 4 & 0 & $0.0002^{* \ddagger}$ \\
\hline IV & 8 & 0 & $<0.001^{* \ddagger}$ \\
\hline Other & 0 & 1 & $0.39^{\ddagger}$ \\
\hline \multicolumn{4}{|l|}{ cT } \\
\hline $1 \mathrm{a}$ & 2 & 63 & $0.0004^{* \ddagger}$ \\
\hline $1 b$ & 10 & 83 & $0.02^{* \ddagger}$ \\
\hline 2 & 5 & 16 & $0.61^{\ddagger}$ \\
\hline 3 & 3 & 5 & $0.30^{\ddagger}$ \\
\hline $4 a$ & 15 & 0 & $<0.001^{* \ddagger}$ \\
\hline $4 \mathrm{~b}$ & 1 & 0 & $0.39^{\ddagger}$ \\
\hline Other & 0 & 2 & $0.78^{\ddagger}$ \\
\hline \multicolumn{4}{|l|}{$\mathrm{cN}$} \\
\hline 0 & 21 & 162 & $<0.001^{* \ddagger}$ \\
\hline 1 & 6 & 4 & $0.001^{* \ddagger}$ \\
\hline 2 & 6 & 2 & $0.0001^{* \ddagger}$ \\
\hline 3 & 2 & 0 & $0.03^{* \ddagger}$ \\
\hline $\mathrm{X}$ & 1 & 1 & $0.78^{\ddagger}$ \\
\hline \multicolumn{4}{|l|}{$\mathrm{cM}$} \\
\hline 1 & 3 & 0 & $0.003^{* \ddagger}$ \\
\hline 0 & 33 & 168 & $0.017^{* \ddagger}$ \\
\hline $\mathrm{x}$ & 0 & 1 & $0.39^{\ddagger}$ \\
\hline \multicolumn{4}{|l|}{ Reconstruction method } \\
\hline B-I (manual) & 1 & 74 & $<0.001^{* \ddagger}$ \\
\hline B-I (posterior-wall perforation) & 8 & 48 & $0.58^{\ddagger}$ \\
\hline B-I (HDST) & 2 & 27 & $0.17^{\ddagger}$ \\
\hline $\mathrm{R}-\mathrm{Y}$ & 25 & 20 & $<0.001^{* \ddagger}$ \\
\hline Surgical time (min, mean \pm SD) & $245.1 \pm 48.9$ & $300.4 \pm 62.0$ & $<0.001^{* \dagger}$ \\
\hline Bleeding volume $(\mathrm{mL}$, mean $\pm \mathrm{SD})$ & $333.6 \pm 175.3$ & $101.0 \pm 112.4$ & $<0.001^{* \dagger}$ \\
\hline Number of days of postoperative hospitalization (mean \pm SD) & $27.4 \pm 20.5$ & $18.5 \pm 5.2$ & $0.014^{* \dagger}$ \\
\hline Number of lymph nodes dissected (mean \pm SD) & $23.7 \pm 12.8$ & $25.9 \pm 13.3$ & $0.35^{\dagger}$ \\
\hline Incidence of postoperative complications (\%) & 5 (13.9) & $21(12.4)$ & $0.97^{\ddagger}$ \\
\hline Incidence of procedural accidents $(\%)^{\S}$ & $0(0.0)$ & $2(1.2)$ & $0.78^{\ddagger}$ \\
\hline
\end{tabular}

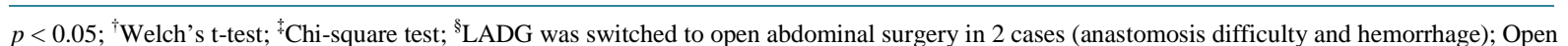
distal gastrectomy (ODG); laparoscopic assisted distal gastrectomy (LADG). 
time period confirms evidence from previous reports of clinical trials that LADG is less invasive [6] [21]. Nonetheless, our study of LADG vs. ODG in the real world could not conclude that LADG is less invasive, but that it is as good as ODG, as the non-inferiority of LADG to ODG has been proved by clinical trials. We also did not observe any recurrence of disease nor any deaths.

In our review of reconstructive procedures, we observed that manual anastomosis had been completely replaced by mechanical approaches by 2007, after which both posterior-wall perforation and HDST were used with the B-I procedure. Beginning in 2008, reconstruction was performed using posterior-wall perforation or the $\mathrm{R}-\mathrm{Y}$ procedure. These procedural changes can be attributed to the fact that mechanical anastomosis is evidently less time-consuming than manual anastomosis and that posterior-wall perforation is considered more reliable because it enables closure of the stapler insertion point under direct vision. The R-Y procedure was occasionally selected in patients with a small residual stomach, or those who had complications such as esophageal hiatal hernia [15]-[18].

The trend towards greater use of LADG that we observed over the period of study is probably influenced by the fact that nowadays more than half of all patients in Japan undergoing surgery for gastric cancer are in the early stages of this disease. Surgeons may also have become increasingly aware of the need for financial economy. The issue of technical fees paid by insurers to cover laparoscopic surgery for solid cancers was raised in the draft plan of the healthcare reimbursement system revision for fiscal year 2012 in Japan [22]. Furthermore, the Diagnosis Procedure Combination (DPC) index, which affects the management of hospitals under the DPC system, may incorporate evaluation of the practical usefulness of cancer treatment regional referral fees as a factor to promote shorter hospital stays and regional linkage in patient care [23]. The regional referral pathway for cancer treatment for the care of patients in relatively early stages of cancer has begun to be promoted in many prefectures.

In response to calling for a multicenter randomized controlled trial of LADG versus ODG to establish LADG as a standard therapy [4] [21], the Japan Clinical Oncology Group (JCOG) conducted a prospective multicenter phase II study (JCOG0703) designed to demonstrate the safety and feasibility of LADG for advanced stage I gastric cancer. The LADG procedure was considered sufficiently safe to proceed to a phase III study (JCOG0912) to confirm overall survival rates [7]. It is essential that surgeons continue to develop their knowledge and skills in performing LADG, and are aware of the evidence obtained from the JCOG study [7], and there is a need for the establishment of a valid educational program in laparoscopic surgery. In the future, we expect to see the trend towards preferential application of LAG in general as well as specialized facilities, and for LAG to be established as a standard therapy.

This study has several limitations. Because the study examines a 10 years period, the treatments and procedures used during that time have been advanced. Furthermore, the cases are biased at the two facilities. On these points, this study needs to be interpreted with care. Nonetheless, no study of one operating surgeon who was responsible for operating and advising on all study cases of LADG and ODG for a period of 10 years has been reported to the best of our knowledge, and this could be advantageous to evaluate the clinical efficacy and safety of LADG without having to take into account multiple surgeons' technical levels or the background differences between the facilities.

In conclusion, this study showed that LADG had results similar to previous studies even though there was only one operating and advising surgeon for all the cases [8] [24] [25]. Previous studies comparing LADG with ODG indicated that the surgeons' technical experience and abilities could influence the clinical efficacy and safety of the procedures. LADG in the real world had factors that impaired the merit of LADG as a less invasive procedure, such as the necessity of reconstruction procedures, financial considerations, and the influence of hospital policies. Our study revealed that not only procedural techniques, but also environmental improvements, are necessary to maximize the benefits of LADG. A further prospective cohort study with a large sample size including environmental factors is needed to verify the results from this study.

\section{Disclosure}

There is no conflict of interest.

\section{References}

[1] Kitano, S., Iso, Y., Moriyama, M. and Sugimachi, K. (1994) Laparoscopy-Assisted Billroth I Gastrectomy. Surgical 
Laparoscopy, Endoscopy, 4, 146-148.

[2] Shiraishi, N., Adachi, Y., Kitano, S., Bandoh, T., Katsuta, T. and Morimoto, A. (1999) Indication for and Outcome of Laparoscopy-Assisted Billroth I Gastrectomy. British Journal of Surgery, 86, 541-544. http://dx.doi.org/10.1046/j.1365-2168.1999.01083.x

[3] Kitano, S., Adachi, Y., Shiraishi, N., Suematsu, T. and Bando, T. (1999) Laparoscopic-Assisted Proximal Gastrectomy for Early Gastric Carcinomas. Surgery Today, 29, 389-391. http://dx.doi.org/10.1007/BF02483072

[4] Shiraishi, N., Yasuda, K. and Kitano, S. (2006) Laparoscopic Gastrectomy with Lymph Node Dissection for Gastric Cancer. Gastric Cancer, 9, 167-176. http://dx.doi.org/10.1007/s10120-006-0380-9

[5] Etoh, T., Shiraishi, N. and Kitano, S. (2009) Current Trends of Laparoscopic Gastrectomy for Gastric Cancer in Japan. Asian Journal of Endoscopic Surgery, 2, 18-23. http://dx.doi.org/10.1111/j.1758-5910.2009.00003.X

[6] Yacoub, D., Athanasiou, T., Tekkis, P. and Hanna, G.B. (2009) Laparoscopic Assisted Distal Gastrectomy for Early Gastric Cancer: Is It an Alternative to the Open Approach? Surgical Oncology, 18, 322-333. http://dx.doi.org/10.1016/j.suronc.2008.08.006

[7] Katai, H., Sasako, M., Fukuda, H., Nakamura, K., Hiki, N., Saka, M., Yamaue, H., Yoshikawa, T., Kojima, K. and JCOG Gastric Cancer Surgical Study Group (2010) Safety and Feasibility of Laparoscopy-Assisted Distal Gastrectomy with Suprapancreatic Nodal Dissection for Clinical Stage I Gastric Cancer: A Multicenter Phase II Trial (JCOG 0703). Gastric Cancer, 13, 238-244. http://dx.doi.org/10.1007/s10120-010-0565-0

[8] Adachi, Y., Shiraishi, N., Shiromizu, A., Bandoh, T., Aramaki, M. and Kitano, S. (2000) Laparoscopy-Assisted Billroth I Gastrectomy Compared with Conventional Open Gastrectomy. Archives of Surgery, 135, 806-810. http://dx.doi.org/10.1001/archsurg.135.7.806

[9] Lee, S.E., Kim, Y.W., Lee, J.H., Ryu, K.W., Cho, S.J., Lee, J.Y., Kim, C.G., Choi, J.I., Kook, M.C., Nam, B.H., Park, S.R., Kim, M.J. and Lee, J.S. (2009) Developing and Institutional Protocol Guideline for Laparoscopy-Assisted Distal Gastrectomy. Annals of Surgical Oncology, 16, 2231-2236. http://dx.doi.org/10.1245/s10434-009-0490-9

[10] Japanese Gastric Cancer Association (1999) Japanese Classification of Gastric Carcinoma. 13th Edition.

[11] Donohue, J.H. (2003) Distal Gastrectomy. Operative Techniques in General Surgery, 5, 3-13. http://dx.doi.org/10.1053/otgn.2003.35354

[12] Kitano, S., Shiraishi, N., Kakisako, K., Yasuda, K., Inomata, M. and Adachi, Y. (2002) Laparoscopy-Assisted Billroth-I Gastrectomy (LADG) for Cancer: Our 10 Years’ Experience. Surgical Laparoscopy Endoscopy \& Percutaneous Techniques, 12, 204-207. http://dx.doi.org/10.1097/01.SLE.0000017663.43677.6E

[13] Ahn, C.W., Hur, H., Han, S.U. and Cho, Y.K. (2013) Comparison of Intracorporeal Reconstruction after Laparoscopic Distal Gastrectomy with Extracorporeal Reconstruction in the View of Learning Curve. Journal of Gastric Cancer, 13, 34-43. http://dx.doi.org/10.5230/jgc.2013.13.1.34

[14] Hosoya, Y., Lefor, A., Hyodo, M., Zuiki, T., Haruta, H., Kurashina, K., Saito, S. and Yasuda, Y. (2009) Gasless Laparoscopic Distal Gastrectomy with Roux-en-Y reconstruction. Hepato-Gastroenterology, 56, 1571-1575.

[15] Schweizer, W., Blunschi, T., Gertsch, P. and Blumgart, L.H. (1990) Postoperative Course Following Stomach Resection: A Comparison of Billroth I, Billroth II and Roux-en-Y resection-reconstruction. Swhweiz Med Wochenschr, 120, 521-528.

[16] Nunobe, S., Okaro, A., Sasako, M., Saka, M., Fukagawa, T., Katai, H. and Sano, T. (2007) Billroth I versus Roux-en Y Reconstructions: A Quality of Life Survey at 5 Years. International Journal of Clinical Oncology, 12, 433-439. http://dx.doi.org/10.1007/s10147-007-0706-6

[17] Ishikawa, M., Kitayama, J., Kaizaki, S., Nakayama, H., Ishigami, H., Fujii, S., Suzuki, H., Inoue, T., Sako, A., Asakage, M., Yamashita, H., Hatono, K. and Nagawa, H. (2005) Prospective Randomized Trial Comparing Billroth I and Roux-en-Y Procedures after Distal Gastrectomy for Gastric Carcinoma. World Journal of Surgery, 29, 1415-1420. http://dx.doi.org/10.1007/s00268-005-7830-0

[18] Kojima, K., Yamada, H., Inokuchi, M., Kawano, T. and Sugihara, K. (2008) A Comparison of Roux-en Y and Billroth-I Reconstruction after Laparoscopy-Assisted Distal Gastrectomy. Annals of Surgery, 247, 962-967. http://dx.doi.org/10.1097/SLA.0b013e31816d9526

[19] Fukunaga, T., Kidokoro, A., Fukunaga, M., Iba, T., Fuse, S., Nagakari, K., Suda, M. and Yoshikawa, S. (2003) Clipless D2 Laparoscopy-Assisted Distal Gastrectomy: Experience with LigaSure AtlasTM. Asian Journal of Endoscopic Surgery, 8, 267-271.

[20] Fukunaga, T., Kidokoro, A., Fukunaga, M., Nagakari, K., Suda, M., Yoshikawa, S. and Ogasawara, T. (2003) Application LigaSureTM in Laparoscopy-Assisted Gastrectomy with Lymph Node Dissection. Asian Journal of Endoscopic Surgery, 8, 391-396.

[21] Kim, M.C., Kim, K.H., Kim, H.H. and Jung, G.J. (2005) Comparison of Laparoscopy-Assisted by Conventional Open 
Distal Gastrectomy and Extraperigastric Lymph Node Dissection in Early Gastric Cancer. Journal of Surgical Oncology, 91, 90-94. http://dx.doi.org/10.1002/jso.20271

[22] Ministry of Health, Labour and Welfare, Medical Support Division Department of Insurance (2012) Outline of Revision for Remuneration for Medical Care. www.mhlw.go.jp/bunya/iryouhoken/iryouhoken15/dl/gaiyou.pdf

[23] Yasunaga, H., Ide, H., Imamura, T. and Ohe, K. (2005) Impact of the Japanese Diagnosis Procedure Combination-Based Payment System on Cardiovascular Medicine-Relate Costs. International Heart Journal, 46, 855-866. http://dx.doi.org/10.1536/ihj.46.855

[24] Zhao, Y., Yu, P., Hao, Y., Qian, F., Tang, B., Shi, Y., Luo, H. and Zhang, Y. (2011) Comparison of Outcomes for Laparoscopically Assisted and Open Radical Gastrectomy with Lymphadenectomy for Advanced Gastric Cancer. Surgical Endoscopy, 25, 2960-2966. http://dx.doi.org/10.1007/s00464-011-1652-y

[25] Martinez-Ramos, D., Miralles-Tena, J.M., Cuesta, M.A., Escrig-Sos, J., Van der Peet, D., Hoashi, J.S. and SalvadorSanchís, J.L. (2011) Laparoscopy versus Open Surgery for Advanced and Resectable Gastric Cancer: A Meta-Analysis. Revista Espanola de Enfermedades Digestivas, 103, 133-141. http://dx.doi.org/10.4321/S1130-01082011000300005

\section{Abbreviation}

LADG: Laparoscopy assisted distal gastrectomy ODG: Open distal gastrectomy

B-I: Billroth-I

DG: Distal gastrectomy

R-Y: Roux-en-Y

TG: Total gastrectomy

HDST: Hemi-double-stapling technique

LAPPG: Pylorus-preserving gastrectomy

LATG: Total gastrectomy

LAPG: Proximal gastrectomy

LECS: Endoscopic cooperative surgery

DPC: Diagnosis Procedure Combination

JCOG: Japan Clinical Oncology Group 